\title{
Modelling the clonal growth of the rhizomatous macrophyte Potamogeton perfoliatus
}

\author{
Susanne R. Wolfer ${ }^{\mathrm{a}, *}$, Egbert H. van Nes ${ }^{\mathrm{b}}$, Dietmar Straile ${ }^{\mathrm{a}}$ \\ ${ }^{a}$ Limnological Institute, University of Konstanz, D-78457 Konstanz, Germany \\ ${ }^{\mathrm{b}}$ Department of Environmental Sciences, Aquatic Ecology and Water Quality Management Group, Wageningen University, \\ P.O. Box 8080, NL-6700 DD Wageningen, The Netherlands
}

Received 29 September 2004; received in revised form 19 May 2005; accepted 2 June 2005

Available online 6 September 2005

\begin{abstract}
Macrophytes play a crucial role in the functioning of lake ecosystems. Until now most macrophyte models neglected the fact that the majority of macrophyte species expand clonally during the growing season. Inclusion of a detailed description of clonal growth in models can facilitate our understanding of space occupation and patch expansion and predict future macrophyte development. "CLOMO" is an individual-based model which includes a detailed, spatially explicit description of rhizome formation and clone expansion as well as a realistic description of photosynthesis including light limitation and temperature. The model also accounts for transfers of energy or resources between different parts of the clone ("clonal integration").

Although the clonal growth of macrophytes is complex and poorly known, the first model results for the macrophyte species Potamogeton perfoliatus were promising and compared well with the field data. The model can produce growth networks very similar to those found in the field. A Monte Carlo sensitivity analysis showed systematically which parameters have the largest effect on the architecture and expansion of the clones.

The application of the model provided new insights into growth dynamics and patch development: (1) the model showed that a lack of branching will lead to the extinction of the clone after a certain number of years. This is due to the fact that the reproductive organs (turions) are formed at the end of a branch and even a small turion mortality will cause a reduction in surviving plant numbers; (2) the growth of rhizome axes relative to those in the previous year determines the patch density and patch expansion rate. Reversing rhizomes lead to compact patch growth whereas continuing rhizomes lead to loose aggregates. (c) 2005 Elsevier B.V. All rights reserved.
\end{abstract}

Keywords: Potamogeton perfoliatus; Aquatic vegetation; Lake Constance; Individual-based model; Ramet; Clonal architecture; Clonal integration

* Corresponding author. Tel.: +497531883364 ; fax: +497531883533.
E-mail address: Susanne.Wolfer@uni-konstanz.de (S.R. Wolfer).

Konstanzer Online-Publikations-System (KOPS)

URL: http://www.ub.uni-konstanz.de/kops/volltexte/2007/3841/

URN: http://nbn-resolving.de/urn:nbn:de:bsz:352-opus-38416 


\section{Introduction}

The majority of submersed macrophytes form clones which are connected by below-ground rhizomes. Observed from above, a macrophyte patch appears like a simple collection of shoots, but a closer look into the sediment reveals a complex network of "ramets" (=potentially independent units with leafy shoot and roots) interconnected by "rhizomes" (=horizontal shoots lacking chlorophyll). One plant of Potamogeton perfoliatus can, for example, consist of more than 15 ramets connected by more than $1 \mathrm{~m}$ of rhizome (Wolfer and Straile, 2004a). Experiments have shown that ramets exchange energy or resources through these rhizomes (Hartnett and Bazzaz, 1983), a process called "clonal integration". Furthermore, rhizomes are mobility units, as a clone can move slowly by creating new rhizomes. The architectural growth of main rhizome axes, rhizome branchings, rhizome angles and rhizome "spacers" (=rhizome connection between two neighbouring shoots) follows species-specific clonal rules (Callaghan et al., 1990; Evans and Cain, 1995). Nonetheless, spacer lengths and branch angles also show considerable variation (Cain et al., 1995; Wolfer and Straile, 2004a,b), sometimes in response to their growth conditions (De Kroon and Hutchings, 1995), aiming at the effective exploitation of local resources such as light and nutrients (Callaghan et al., 1990).

Clonal growth architecture is important for macrophyte fitness, because it determines propagation, growth and survival, space occupation and patch expansion. Also the sharing of resources such as carbohydrates or nutrients increases fitness (Wijesinghe and Handel, 1994; Stuefer et al., 1996; Hutchings and Wijesinghe, 1997).

Our objective was to develop a model which can improve our understanding of mechanisms that could cause the observed field patterns of clonal architecture and patch expansion. It does not aim at replacing existing models of aquatic macrophytes, but rather adds a supplementary application. On the long run it could be used to predict future macrophyte development and the impact of environmental variation.

Although there are many detailed dynamical models of macrophytes (Collins and Wlosinski, 1989; Scheffer et al., 1993; Hootsmans, 1994; Chen and Coughenour, 1996; Muhammetoglu and Soyupak, 2000; Van Nes et al., 2003), the clonal growth of submerged macrophytes has, to our knowledge, never been modelled in detail, including architectural, spatial, environmental, temporal and demographic components. For terrestrial plants, only a few of such detailed models exists (Herben and Suzuki, 2002; Oborny and Kun, 2002). The facts that photosynthesis in water has fundamentally other restrictions than in air and that light submission in water is far more complex require separate models for submersed species.

Here we present the individual-based model "CLOMO" ("clonal module"), a spatially explicit model that combines a stochastic description of clonal expansion with a ramet-based calculation of primary production and respiration using physiological rules of the non-clonal model Charisma (Van Nes et al., 2002, 2003). Clonal integration was described as simple as possible, since transport between ramets is a poorly understood process. We applied the model to describe the spatial architecture of $P$. perfoliatus L. in Lake Constance.

Special analyses were performed with regard to branching frequency and rhizome growth direction. Furthermore, a Monte Carlo sensitivity analysis (Klepper et al., 1994) was applied to show systematically which parameters have the largest effect on the architecture and expansion of the clones.

\section{Methods}

\subsection{Model description}

\subsubsection{Overview}

CLOMO is an extension of the model Charisma (Van Nes et al., 2002, 2003). Although CLOMO uses the biomass growth unit of Charisma, its new components make it fundamentally different from the earlier version (see Table 1). While the biomass model Charisma is non-clonal and uses super-individuals to cope with large numbers of individuals (Scheffer et al., 1995), the current model is truly individual-based and operates on a smaller spatial scale. Clones are modelled as a set of ramets (nodes with shoots) interconnected by rhizomes. The model is explicitly spatial, describing patches of plants growing on a grid.

The basic units of the calculations are the ramets. Each ramet has an exact $x$ and $y$ coordinate and 
Table 1

An overview of the main differences between non-clonal macrophyte models (e.g. Collins and Wlosinski, 1989; Scheffer et al., 1993; Hootsmans, 1994; Chen and Coughenour, 1996; Muhammetoglu and Soyupak, 2000; Van Nes et al., 2003) and the clonal growth model CLOMO

\begin{tabular}{|c|c|}
\hline Non-clonal macrophyte models & Clonal macrophyte model \\
\hline $\begin{array}{l}\text { Shoots are the basic unit for photosynthesis (self-) shading is calculated } \\
\text { for each shoot }\end{array}$ & Ramets are the basic unit for photosynthesis \\
\hline $\begin{array}{l}\text { From each seed or tuber emerges a maximum of one shoot in spring; no } \\
\text { further shoot emergence during the growth season }\end{array}$ & $\begin{array}{l}\text { From each tuber emerges one ramet in spring; additional ramets } \\
\text { are formed during the growth season if there is enough biomass } \\
\text { accumulated }\end{array}$ \\
\hline Individual shoots, no clones & Several ramets form a clone \\
\hline (Almost) all shoots are assumed to be of equal age and length & Each ramet has a different age and length \\
\hline Spacer lengths and number of ramets per clone are ignored & $\begin{array}{l}\text { Spacer lengths and number of ramets per clone are important } \\
\text { components }\end{array}$ \\
\hline No patch expansion within a season & $\begin{array}{l}\text { Position of new ramets is determined stochastically and leads to } \\
\text { patch expansion within a season }\end{array}$ \\
\hline Transfer of energy between shoots and roots/reproductive organs only & Additional transfer of energy between ramets \\
\hline
\end{tabular}

is associated with one grid cell. A clone can expand over more than one grid cell. The biomass growth of each ramet is calculated with time steps of 1 day and depends on photosynthesis and local environmental conditions. During their growth, the shoots reserve an increasing part of their net production for creating rhizomes and new ramets. The positioning of new ramets is determined by the length of the rhizome and a stochastic component. Above a certain shoot length, part of the production will be transferred to neighbouring ramets (clonal integration). During one season, apical growth of rhizomes and ramets and branching leads to the origin of a large clonal system ("plant"). At the end of the growth season, part of the biomass is redirected to overwintering organs ("turions") in the sediment, and the rest of the aboveground biomass dies. The turions will develop new sprouts at a preset day in spring. Many of the default parameters have been derived from Lake Constance field data (Table 2).

Each grid cell has environmental variables associated with it (vertical light attenuation, water level and nutrients). The grid dimensions can be defined by the user.

In the following, we will describe the model focusing on the new features and summarizing the parts that are taken from the earlier version of the model (Van Nes et al., 2002, 2003). The model is implemented in Delphi 5.5, an object oriented version of Pascal. It is freely available on http://www.dow.wau.nl/aew/ charisma/.

\subsubsection{Production and respiration}

Most rules for production and respiration are taken from the Charisma model (Van Nes et al., 2003), but bicarbonate is not assumed to be limiting, and senescence is described in a more detailed way.

The daily growth of each shoot $(\Delta W)$ depends on the photosynthesis $(P)$, the maintenance respiration $\left(R_{\mathrm{m}}\right)$, the import from previous ramets $\left(T_{1}\right)$ and export to subsequent ramets $\left(T_{2}\right)$ (Fig. 1):

$$
\Delta W_{\mathrm{s}}=W_{\mathrm{s}} P-W R_{\mathrm{m}}+T_{1}-T_{2}
$$

Maintenance respiration $\left(R_{\mathrm{m}}\right)$ is arbitrarily taken in the middle of the range of values published by Madsen and Adams (1989) and Ikusima (1970) for miscellaneous submerged plants $\left(r_{20}=0.024 \mathrm{gg}^{-1} \mathrm{~d}^{-1}\right.$ at

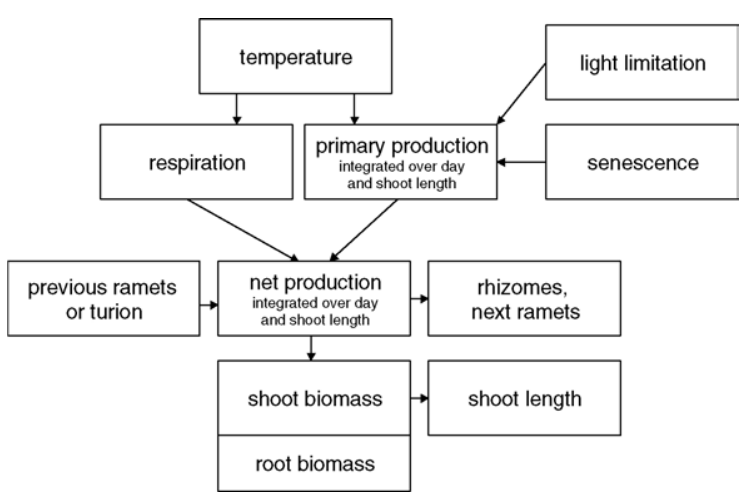

Fig. 1. Schematic overview of the factors that determine the growth of each shoot. 
Table 2

Default parameters for the clonal model of Potamogeton perfoliatus in Lake Constance

\begin{tabular}{|c|c|c|c|}
\hline Parameter & Description & Unit & Value \\
\hline HAge & Half saturation for senescence & day & $100^{\mathrm{a}}$ \\
\hline PAge & Exponent in Hill function for senescence & & $2^{\mathrm{a}}$ \\
\hline pMax & Maximal gross photosynthesis & $\mathrm{h}^{-1}$ & $0.006^{\mathrm{b}}$ \\
\hline$Q_{10}$ & $Q_{10}$ for maintenance respiration & & $2^{\mathrm{c}}$ \\
\hline Resp20 & Respiration at $20^{\circ} \mathrm{C}$ & day $^{-1}$ & $0.00206^{\mathrm{a}}$ \\
\hline MaxLength & Maximum shoot length & $\mathrm{m}$ & $5^{\mathrm{a}}$ \\
\hline MaxWeightLenRatio & Mean weight of $1 \mathrm{~m}$ young shoot & $\mathrm{g} \mathrm{m}^{-1}$ & $0.8^{\mathrm{e}}$ \\
\hline RootShootRatio & Proportion of shoot allocated to the roots & Fraction & $0.06^{\mathrm{a}}$ \\
\hline FracPeriphyton & Fraction of light reduced by periphyton & Fraction & $0.2^{\mathrm{c}}$ \\
\hline hPhotoLight & Half-saturation light intensity (PAR) for photosynthesis & $\mu \mathrm{Em}^{-2} \mathrm{~s}^{-1}$ & $30^{\mathrm{c}}$ \\
\hline hPhotoTemp & Half-saturation temperature for photosynthesis & ${ }^{\circ} \mathrm{C}$ & $14^{\mathrm{c}}$ \\
\hline pPhotoTemp & Exponent in temperature effect (Hill function) for photosynthesis & & $3^{\mathrm{c}}$ \\
\hline sPhotoTemp & Scaling of temperature effect for photosynthesis & & $1.35^{\mathrm{c}}$ \\
\hline HTurbReduction & Half saturation biomass of light attenuation reduction & $\mathrm{g} \mathrm{m}^{-2}$ & $100^{\mathrm{c}}$ \\
\hline pTurbReduction & Power in Hill function of light attenuation reduction & & $1^{\mathrm{c}}$ \\
\hline PlantK & Light attenuation of plant tissue & $\mathrm{m}^{2} \mathrm{~g}^{-1}$ & $0.02^{\mathrm{c}}$ \\
\hline cTuber & Fraction of turion weight lost daily when sprouts start growing & Fraction & $0.1^{\mathrm{c}}$ \\
\hline MaxTurionWeight & Maximum weight of turions & $\mathrm{g}$ & $0.2^{\mathrm{a}}$ \\
\hline MeanTurionWeight & Mean (initial) weight of turions & $\mathrm{g}$ & $0.2^{\mathrm{a}}$ \\
\hline MinTurionWeight & Minimum weight of turions & $\mathrm{g}$ & $0.1^{\mathrm{a}}$ \\
\hline TurionFraction & Fraction of biomass allocated to turions & Fraction & $0.05^{\mathrm{b}}$ \\
\hline TurionGerminationDay & Day of turion sprouting & & $114^{\mathrm{a}}$ \\
\hline TurionMortality & Annual mortality of turions & $\mathrm{yr}^{-1}$ & $0.1^{\mathrm{a}}$ \\
\hline TurionReproDay & Formation day of turions & & $250^{\mathrm{a}}$ \\
\hline Alpha & $\begin{array}{l}\text { Parameter that determines the biomass allocation to subsequent } \\
\text { rhizomes and ramets }\end{array}$ & & $0.6^{\mathrm{b}}$ \\
\hline MeanRhiAngle & Mean rhizome angle & $\mathrm{rad}$ & $0^{\mathrm{d}}$ \\
\hline NewRametLength & Length of the ramet at which it creates a new rhizome and ramet & $\mathrm{m}$ & $0.15^{\mathrm{b}}$ \\
\hline PBranchingLong & Branching probability of rhizomes & Fraction & $0.1^{\mathrm{d}}$ \\
\hline RhizomeWeightPerM & Average weight of $1 \mathrm{~m}$ rhizome & $\mathrm{g} \mathrm{m}^{-1}$ & $0.5^{\mathrm{e}}$ \\
\hline SDRhiAngle & Standard deviation of rhizome angle & $\mathrm{rad}$ & $\pi / 9^{d}$ \\
\hline TurionAngle & Angle of the turion with the parent rhizome & $\mathrm{rad}$ & $\pi^{\mathrm{d}}$ \\
\hline TurionAngleRange & Range in the angle of the turion with the parent rhizome & rad & $0^{\mathrm{d}}$ \\
\hline
\end{tabular}

a Estimated from field observations (S. Wolfer, Unpublished results).

b Calibrated.

c Assumed to be the same as P. pectinatus (Scheffer et al., 1993; Van Nes et al., 2003).

d Wolfer and Straile (2004b).

e Wolfer and Straile (2004a).

$20^{\circ} \mathrm{C}$ ). Temperature dependence of the respiration is formulated using a $Q_{10}$ formulation (default value 2):

$R_{\mathrm{m}}=r_{20} Q_{10}^{T-20 / 10}$

Only the shoots take part in the primary production $(P)$. The maximum photosynthesis $\left(P_{\max }\right)$ is limited by the in situ light intensity at plant leaves $(I)$, temperature $(T)$, and the age of the ramet $(A)$ :

$P=P_{\max } \frac{I}{I+H_{\mathrm{I}}} \frac{1.35 T^{3}}{T^{3}+14^{3}} \frac{H_{\mathrm{A}}^{2}}{H_{\mathrm{A}}^{2}+A^{2}}$
The parameter $P_{\max }$ represents the specific daily production of the plant top at $20^{\circ} \mathrm{C}$ not having light limitation. Light limitation is described by a Monod function, $H_{\mathrm{I}}$ is the half-saturation constant. Irradiance follows a daily as well as a yearly cycle and light is attenuated in the water column both by the water and the vegetation (Van Nes et al., 2003).

Temperature dependence of photosynthesis was fitted to values of Potamogeton pectinatus (Scheffer et al., 1993). As field observations indicate that older ramets are often covered with periphyton that reduces irradi- 
ance and consequently production, a factor for aging was added as a Hill function $\left(H_{\mathrm{A}}\right.$ is the half-saturation constant of aging).

In the present analyses we assumed that the plants are not limited by phosphorus, nitrogen or carbon in the water, but the model can optionally account for such limitations.

As light varies during the day and with water depth, we integrated photosynthesis over the day and over the length of each shoot by three-point Gaussian integration (Goudriaan, 1986). The in situ light conditions were averaged for each grid cell taking selfshading into account (see below). As accounting for self-shading can be very computer intensive and as the biomass changes are relatively slow, we calculated the light attenuation in each grid cell once in 7 days (at 15 depths distributed evenly over the water column) and interpolated linearly between the calculated points.

For vertical light attenuation, temperature and water level we used 10 years of interpolated data from Lake Constance. For more theoretical questions we averaged these years to avoid stochastic differences between years.

We also included water clarification by macrophytes (Scheffer, 1998; Van Nes et al., 2003). In Lake Constance this effect is probably not important as the water is usually rather clear, but this effect is essential for the existence of alternative stable states (Scheffer, 1998; Van Nes et al., 2002).

In most simulations we used a grid of $10 \times 10$ cells of $0.2 \mathrm{~m} \times 0.2 \mathrm{~m}$. To avoid edge effects, ramets that grew beyond the border of the grid were coupled to the opposite grid cells.

\subsubsection{Biomass allocation, clonal growth and clonal integration (transfer)}

The produced biomass is allocated to shoots, rhizomes and roots. The root is a fixed proportion of the shoot that does not take part in photosynthesis. The height of the young shoots increases proportionally with their biomass until the water surface or a predefined maximum height has been reached. If the net production of a shoot is positive, a part is allocated to the rhizomes. The proportion of the production that is allocated depends on the height of the plant: very small shoots add nothing, whereas fully-grown shoots add all their production to the rhizomes. Between these extremes, the allocated proportion increases linearly

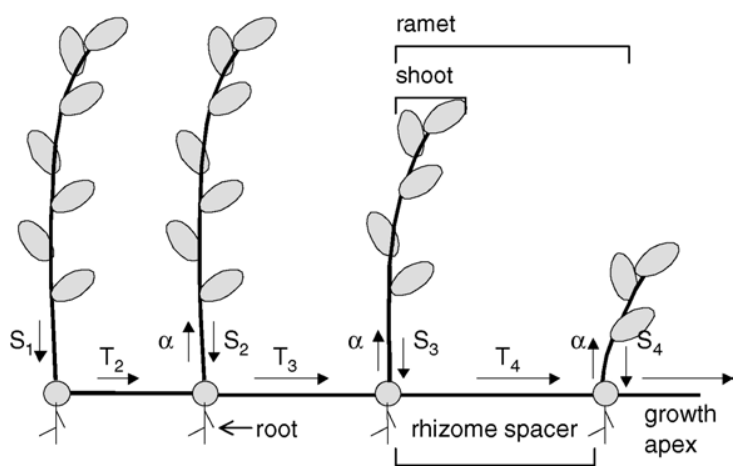

Fig. 2. Scheme of the clonal growth of P. perfoliatus. $S_{i}$ is the surplus production of shoot $i, T_{i}$ is the transfer to shoot $i, \alpha$ is a parameter that determines which part of the transfer $\left(T_{i}\right)$ goes to the next shoot.

with shoot height. The biomass is assumed to be transported acropetally from older to younger ramets (Evans and Whitney, 1992; Marbà et al., 2002). Each younger shoot adds a part $(\alpha)$ of the transferred biomass to its net production. The remainder goes to the next shoot (Fig. 2). Thus, the transport to the shoot of ramet $i\left(T_{i}\right)$ sums up to:

$T_{i}=\sum_{k=1}^{i} S_{i-k} \alpha(\alpha-1)^{k-1} \quad i>1$

in which $S_{i}$ is the surplus production of shoot $i$ ( $i=1$ is the oldest shoot). For simplicity we assume that there is no cost for transport. Biomass which is transferred to full-grown shoots, will not be used but immediately be transferred further to the next ramet. In case of branching, the transported biomass is divided equally over both branches. The surplus production of the last ramet goes into the growth of the new rhizome, which has a fixed weight-length ratio. If the last shoot reaches a certain fixed height, the growth of the rhizome is ceased and a new daughter ramet is created.

The main rhizome may have a (usually small) angle with the previous rhizome, which is drawn from a normal distribution. Each ramet has a certain probability of branching, which is drawn from a Bernoulli distribution. The angle of the branch with the main rhizome is also drawn from a predefined normal distribution.

\subsubsection{Mortality}

The model accounts for (a) a fixed background mortality and (b) mortality at the end of the season. 


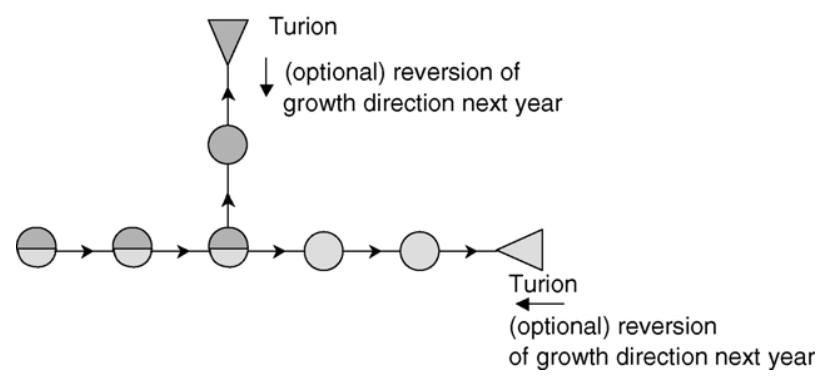

Fig. 3. Schematic representation of a clone and the transport of energy from the ramets (circles) to the turions (triangles). At the end of the season the turions get a proportional part (same color) of the accumulated biomass in the rhizomes and shoots. If enough biomass is accumulated, the turion produces a new clone in the next season in which the growth direction is optionally reversed.

Background mortality results either in a weight loss or in a stochastic loss of the complete shoot depending on whether it has already reached the surface or not (Van Nes et al., 2003). At a pre-set day in autumn, all shoots die, and their biomass is reallocated to the rhizomes. At the last (youngest) ramet of each branch of the clone, a turion is created (Wolfer and Straile, 2004b). Since it has been shown that turion production often depends on plant biomass (Spencer et al., 1993), the turion receives a proportional part of the accumulated energy in each ramet (Fig. 3). The amount of energy (biomass) that is transported to each turion is a fixed part of the rhizome biomass up to a fixed maximum. The turion is only created if the rhizome biomass exceeds a certain minimum weight. The growth direction of the clone can be continuing, reversed or stochastic in the next season.

\subsection{Scanning of asymptotic regimes}

In the previous version of the model we showed that there can be two alternative stable states in the model due to a feedback of vegetation on their light climate (Van Nes et al., 2002, 2003). In the current more detailed model, we show whether the model still has alternative stable states, by analysing of the effect of increasing and decreasing light attenuation on the equilibrium biomass of $P$. perfoliatus. Vertical light attenuation was slowly increased in small steps, while the model was not reset. After a period of stabilising, the biomass at the end of the growth season was plotted for 5 years. When the water had reached maximum vertical light attenuation, and the vegetation had disappeared, the same procedure was repeated backwards (i.e. vertical light attenuation was reduced). A small import of turions prevented total extinction of the plants. If the model has alternative stable states it will show a hysteresis in the response, i.e. the vegetation will recolonise at a lower turbidity than the turbidity at which they disappeared.

\subsection{Monte Carlo sensitivity analysis}

We applied a Monte Carlo sensitivity analysis to select the parameters which have the strongest impact on clonal architecture. We generated 20,000 sets of parameters, drawing all parameters randomly and independently from uniform probability distributions within ranges of $\pm 10 \%$ around the default values. Three years were simulated with each parameter setting, and the model results (mean shoot length, mean spacer length, fraction below-ground biomass, mean number of ramets per clone, approximate expansion area, mean expansion per clone) were stored at three dates (days 189, 219 and 249) of each year. At the end of each simulation, the model was reset to the starting number of turions per grid cell $\left(5 \mathrm{~m}^{-2}\right)$. Sensitivity coefficients were defined by linear regression between the parameter values and each model output value, scaled by the ranges used for each parameter (Klepper, 1989). Cluster analysis (average linkage) was used to form groups of parameters that had the same or opposite effect on the qualitative model results. As similarity measure the absolute sine of the angle between the vectors of sensitivity coefficients was used. As measure of the total sensitivity the length of this vector was used (Klepper, 1989).

In a Monte Carlo analysis there is a probability that a parameter has a positive sensitivity coefficient 


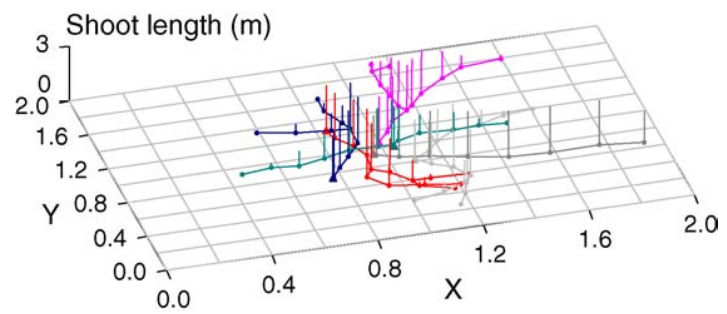

Fig. 4. Example of a generated pattern (clone growth during 1 year).

because it is related to the model outcomes by chance. To determine the significance level of the sensitivity coefficients, we added 100 dummy parameters that had no effect on the model (Van Nes et al., 2003). These dummy parameters were arbitrarily set to 1 . As the real model parameters, the dummy parameters were drawn from uniform distributions, and their "sensitivity coefficients" were calculated. The 0.02 significance level of the sensitivity coefficients was estimated by the $98 \%$ percentile of the sensitivity coefficients of the dummy parameters. In the cluster analyses we only included parameters with a significant sensitivity coefficient.

\section{Results}

\subsection{Architecture and growth parameters}

The simulation produces complex architectural patterns of shoot and rhizome connections (Fig. 4) which compare well with field data from Lake Constance (Wolfer and Straile, 2004b). For example, the observed increase in length of younger rhizomes during one season (Wolfer and Straile, 2004a,b) is reproduced by the model.

A 20-year simulation starting with 5 propagules $\mathrm{m}^{-2}$ yielded the following results: annual curves of most growth parameters (Fig. 5a) start in May, increase more or less exponentially, peak in August, and fall back to 0 after September. With regard to area, there is a net patch growth each year (difference between end-of-season and before-season turion numbers). In a 20-year-simulation (Fig. 5b), biomass, ramet number and total patch size initially increase and then stabilize after 10-15 years; ramet number per plant and rhizome length decrease slightly, spacer length, shoot length, belowground biomass and limitation stay about the same.

The values of simulated growth parameters such as shoot length, rhizome spacer length, rhizome length, etc. are in the range of the field data (Wolfer and Straile, 2004b; Table 3). In general, growth parameters of macrophytes are extremely variable and also the cited reference only covers a small part of the repertoire. The simulated biomass and ramet densities occur frequently in situ (Wolfer, Unpublished observation); for the cited field work, lower densities were deliberately chosen. The simulated number of ramets per plant is rather low, but this is partly due to the high equilibrium density of ramets, implying strong light limitation. At lower ramet densities the number of ramets per plant is quite realistic (Fig. 6).

Stabilization of biomass and ramet number after an initial colonization phase is common in aquatic macrophytes (Duarte and Sand-Jensen, 1990). Ramet number per plant and total rhizome length decrease because of higher density and the resulting light limitation (Wolfer and Straile, 2004a).

Average spacer length, shoot length and belowground fractions do not change much during the 20 simulated years. The behaviour of spacer length does not comply with observations which show that average spacer length decreases with increasing light limitation (Wolfer and Straile, 2004a). This decrease must be an active light foraging strategy of the plants (shoot growth for light capturing at the expense of rhizome growth),

Table 3

Model results of growth parameters in comparison to in situ and mesocosm assessments (average site values)

\begin{tabular}{lccl}
\hline Parameter & Model result & In situ (Wolfer and Straile, 2004b) & Mesocosm (Wolfer and Straile, 2004a) \\
\hline Biomass $\left(\mathrm{g} \mathrm{dw} \mathrm{m}^{-2}\right)$ & 280 & $17-200$ & na \\
Ramets $\left(\mathrm{m}^{-2}\right)$ & 350 & $90-210$ & na \\
Ramets per plant & 5.5 & $5-8$ & $7-13$ \\
Shoot length (cm) & 100 & $12-66$ & na \\
Rhizome spacer length $(\mathrm{cm})$ & 8.5 & $7.6-8$ & $7-10$ \\
Rhizome length $(\mathrm{m})$ & 0.4 & $0.4-0.63$ & $0.6-1.25$ \\
\hline
\end{tabular}


(a)
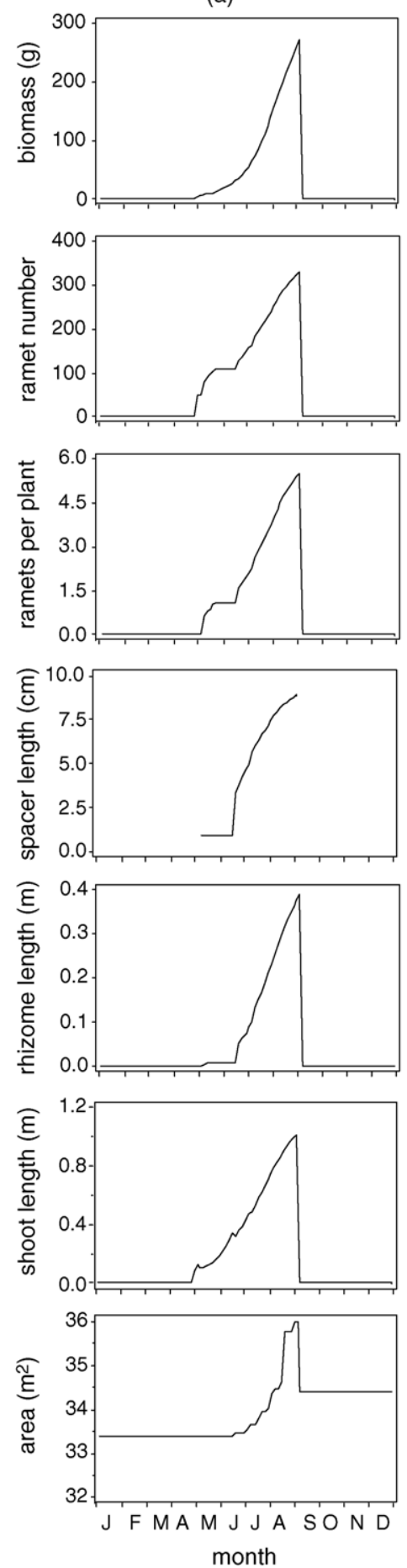

(b)
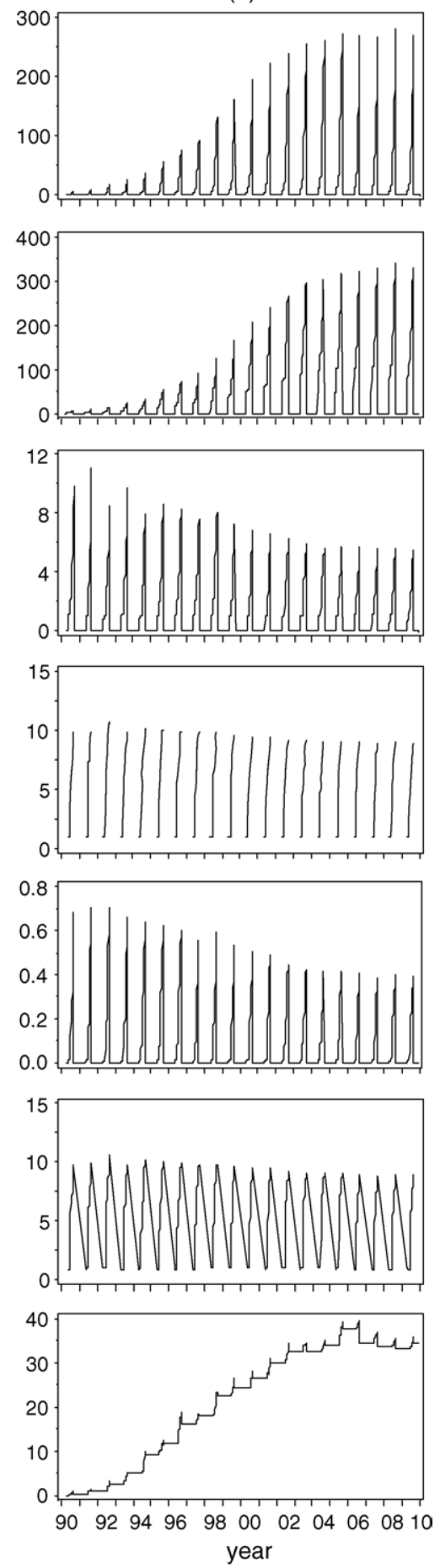

Fig. 5. Twenty years run: (a) year 2009 and (b) 1990-2010. Initial turion density $=1 \mathrm{~m}^{-2}$. 


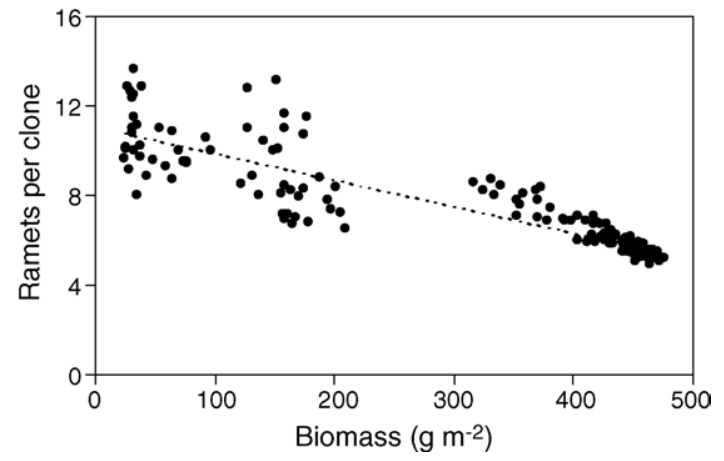

Fig. 6. Relation between the mean number of ramets and biomass at day 249. Data based on 10 replicates of 20 years of simulation. Initial turion density $=1 \mathrm{~m}^{-2}$. The gap between biomass 200 and $300 \mathrm{~g} \mathrm{~m}^{-2}$ is due to the exponential phase of the growth in macrophytes.

which could not be reproduced by the simplified plant strategy in the model.

As in (Wolfer and Straile, 2004a), we found lower patch expansion at low plant density and at higher density, and highest patch expansion at medium density. Long-term stabilization of patch sizes under model conditions (no disturbance, homogeneous environment) is probably related to field observations, where patches appear at the same site and in a very similar size from year to year (Walser, 1996; Gafny and Gasith, 1991). In situ, patches may even keep their distinct shape over long time periods, although, according to expectations, they should expand until they fill up homogeneous lake compartments. The growth curves suggest, that this could be a result of the stabilization of biomass and ramet number which in turn are due to light limitation in a dense patch.

\subsection{Branchings}

A variation of the branching probability per plant from 0 to 1 reveals strong consequences for equilibrium summer biomasses and total number of ramets (Fig. 7). Plants with zero branching die. Due to the clonal growth architecture of $P$. perfoliatus, each plant with zero branching produces exactly one turion at the end of the rhizome axis (Wolfer and Straile, 2004b). Under the assumption of zero mortality, the number of plants will remain the same forever. However, turions are usually subjected to waterbird foraging, fungus infection, or mortality due to stochastic reasons. Addi-
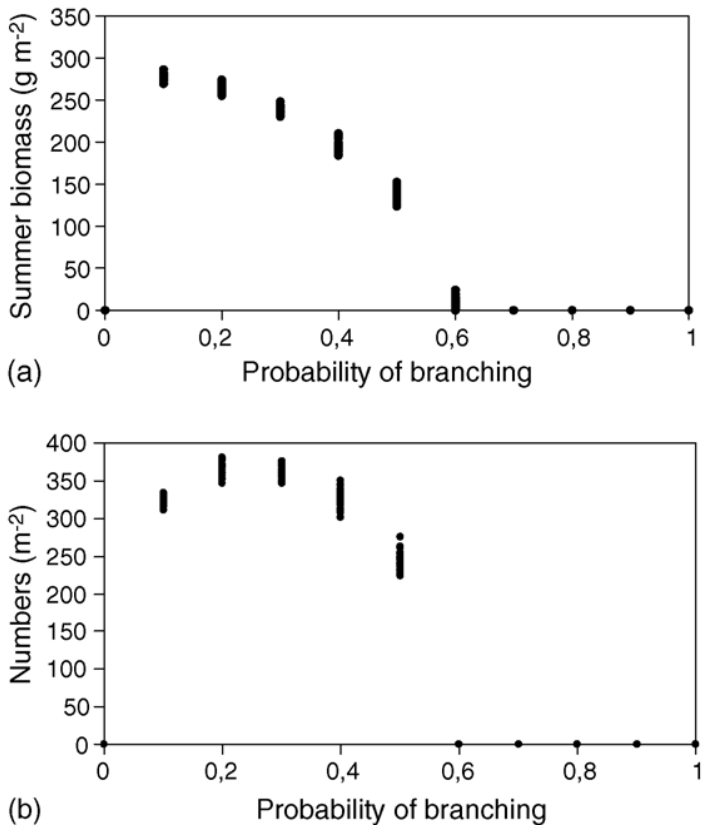

Fig. 7. Modelling results on the influence of branching probability on summer biomass (a) and number of ramets (b) in P. perfoliatus after a simulation period of 20 years.

tionally, it is assumed that turions also fail to propagate if their weight is too low (for example due to bad shoot biomass growth in the previous season). The model shows that, if there is no branching, even the lowest turion mortality will eventually lead to the extinction of the plant.

Maximum summer biomass and maximum density are achieved at the (relatively low) branching intensity of $0.1-0.2$. At higher branching rates, biomass and number of ramets decrease again. The optimum branching probabilities found by the model are equal to those found in the field in patches with favourable plant growth (Wolfer and Straile, 2004b), and lower than those found under experimental conditions (Wolfer and Straile, 2004a), probably because of lower water level and more light in the experimental water basin. The decreasing biomass at higher branching is due to our assumption that energy reserves at the end of the growing season are equally divided up into the number of turions. Branching increases the number of turions, therefore individual turions will not have enough reserves to sprout successfully in the next season. 


\subsection{Spatial expansion with and without reversing turions}

The main rhizomes axes of Potamogeton perfoliatus usually grow relatively straight and terminate with a turion at the end of the season. During winter, the rhizomes decompose and only the turion remains intact. In the following year, the growth of the new rhizome can theoretically (a) be random, (b) continue in the direction of the previous year, or (c) reverse its direction. In practice however, the growth direction of the new rhizome is probably not random but rather determined by the alignment of the meristem (Watson and Cook, 1982). There is some indication of growth reversal, since turions grow basipetally in the sediment in a hook-like fashion (Wolfer and Straile, 2004b).
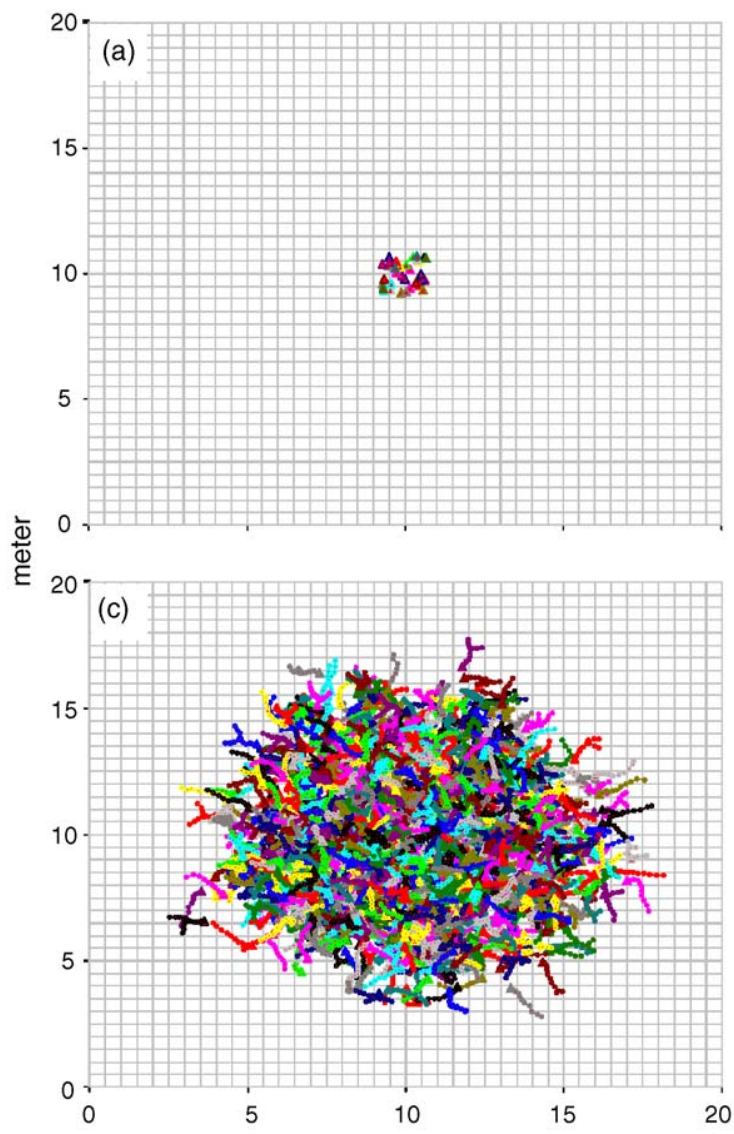

The model allowed us to compare the influence of random, continuing, and reverse rhizome growth. There are dramatic effects on patch density and expansion after a 20-year simulation (Fig. 8). Reversal leads to a very compact patch with high density (Fig. 8a). Continuation of growth into last years direction creates a larger, sparser patch (Fig. 8c) and random growth direction lies in between the two (Fig. 8b).

These model results show that not only extrinsic growth conditions but also intrinsic architectural growth rules are of major importance for the patch characteristics. There are intra-specific feed-backs of patch density and structure such as modification of light, nutrients, and sediment detritus (Cebrián and Duarte, 2001), regulation of flowering (Thompson et al., 1990), or susceptibility against wave attack (Coops
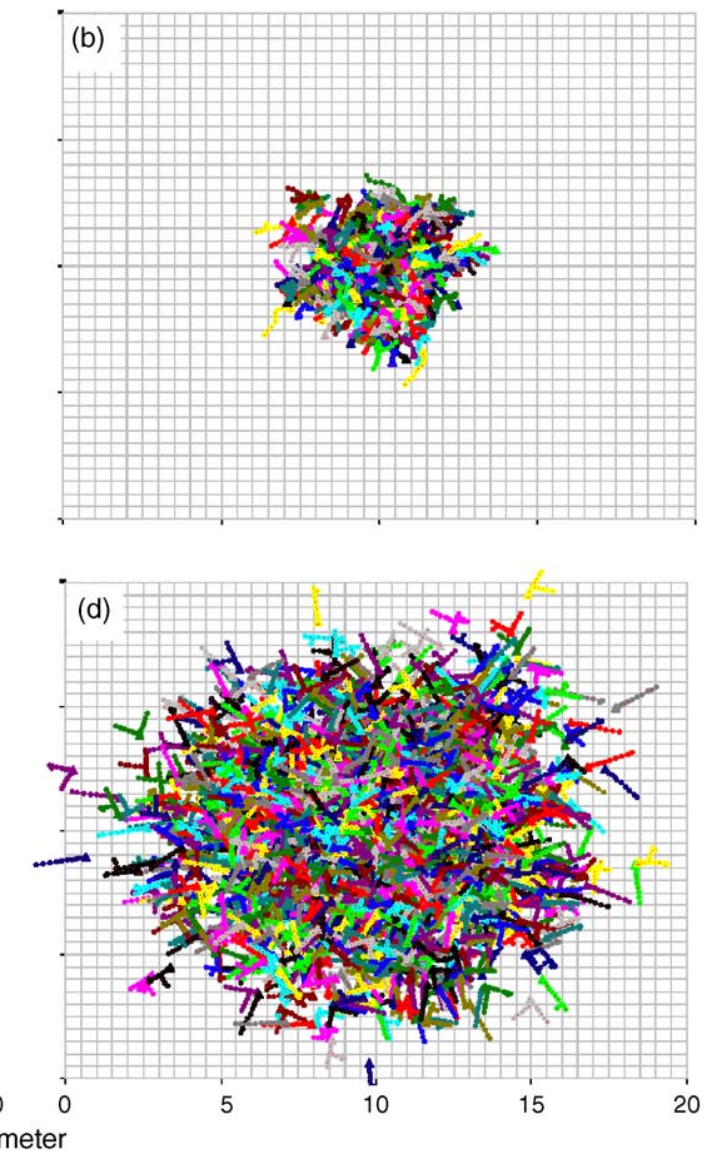

Fig. 8. Patch density and expansion in dependence on rhizome growth direction relative to the previous year. (a) Common starting condition, (b) growth reversal, (c) random growth and (d) continuing growth (simulation period 20 years). 
et al., 1991). The observed differences in patch size, pattern and density will have impacts on processes in the littoral ecosystem, such as element cycles (Barko and James, 1997), as well as on littoral food webs (Lauridsen et al., 1996) and the distribution and agecharacteristics of littoral fish (Weaver et al., 1997) and macro-invertebrates (Webster et al., 1998).

\subsubsection{Scanning of asymptotic regimes}

Although the new model "CLOMO" is much more complex than the original model Charisma, the results were quite similar (Van Nes and Scheffer, 2005). Starting from the turbid state, P. perfoliatus growth tolerates less turbidity, than starting from the clear state. We can therefore show that Potamogeton influences its own environment through feedback mechanisms and that the system can have two alternative stable states at higher turbidity: one with vegetation and one with little or no vegetation. The main difference is that the zone with alternative equilibria is much smaller in the clonal model (Fig. 9), which is due to the fact that P. perfoliatus is assumed to have a smaller effect on water clarity than P. pectinatus.

\subsubsection{Monte Carlo sensitivity analysis of clonal architecture}

Cluster analysis of the sensitivity coefficients shows that there are only two clear clusters of parameters that determine the clonal architecture. The strongest effect is due to a group of parameters with a strong impact on photosynthesis. This group includes hPhotoTemp,

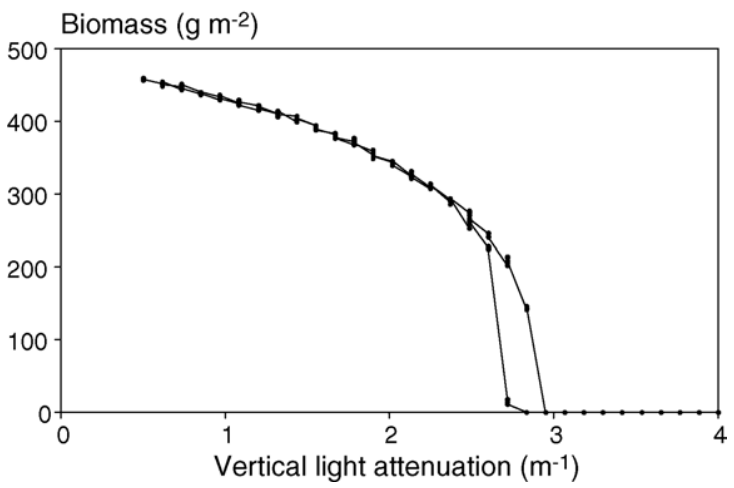

Fig. 9. Simulation of the response of $P$. perfoliatus biomass to increasing and subsequently decreasing turbidity without resetting the model.
pMax, sPhotoTemp and hAge (Fig. 10). These parameters have a strong effect on the expansion area and the number of ramets per clone (Fig. 11). In an earlier analysis, they also had the strongest effect on biomass and numbers in the model Charisma (Van Nes et al., 2003).

A second smaller cluster (Fig. 10) includes the parameter Alpha, which determines the fraction of transported biomass that is used for the growth of subsequent ramets (Fig. 2). The parameters determining the weight-length relationship of the rhizomes (RhizomeWeightPerM) and the length of the shoots at which a new ramet is created (NewRametLength) are also included in this cluster (Fig. 10). These parameters have a strong effect on the clonal expansion because they determine total rhizome length, but also on rhizome spacer length (Fig. 11). Furthermore there are some parameters that belong to no cluster, but also have a significant effect. It seems plausible that the day of turion germination (TurionGerminationDay) influences the growth of the clones, because any additional day of growth increases the biomass. The importance of earlier germination is also confirmed by experiments and in situ observations (Spencer and Rejmanek, 1989; Spencer et al., 2000). In the model, it strongly affects all variables in the first year, but has much less effect in the following years.

\section{Discussion}

\subsection{Comparison with other models}

The models available for clonal plant growth can be classified into empirical models and mechanistic models (Carr et al., 1997).

(1) The majority of aquatic plant models are mechanistic biomass models that calculate plant growth from physiological processes such as photosynthesis but disregard clonal architecture. These models can be (a) non-spatial (Collins and Wlosinski, 1989; Scheffer et al., 1993; van Dijk and Janse, 1993; Davis and McDonnell, 1997; Hootsmans, 1999; Asaeda and Karunaratne, 2000; Calado and Duarte, 2000; Best et al., 2001) or (b) spatial (Wortmann et al., 1997; Van Nes et al., 2003). Compared to such models our model needs many 
Dendrogram using Average linkage

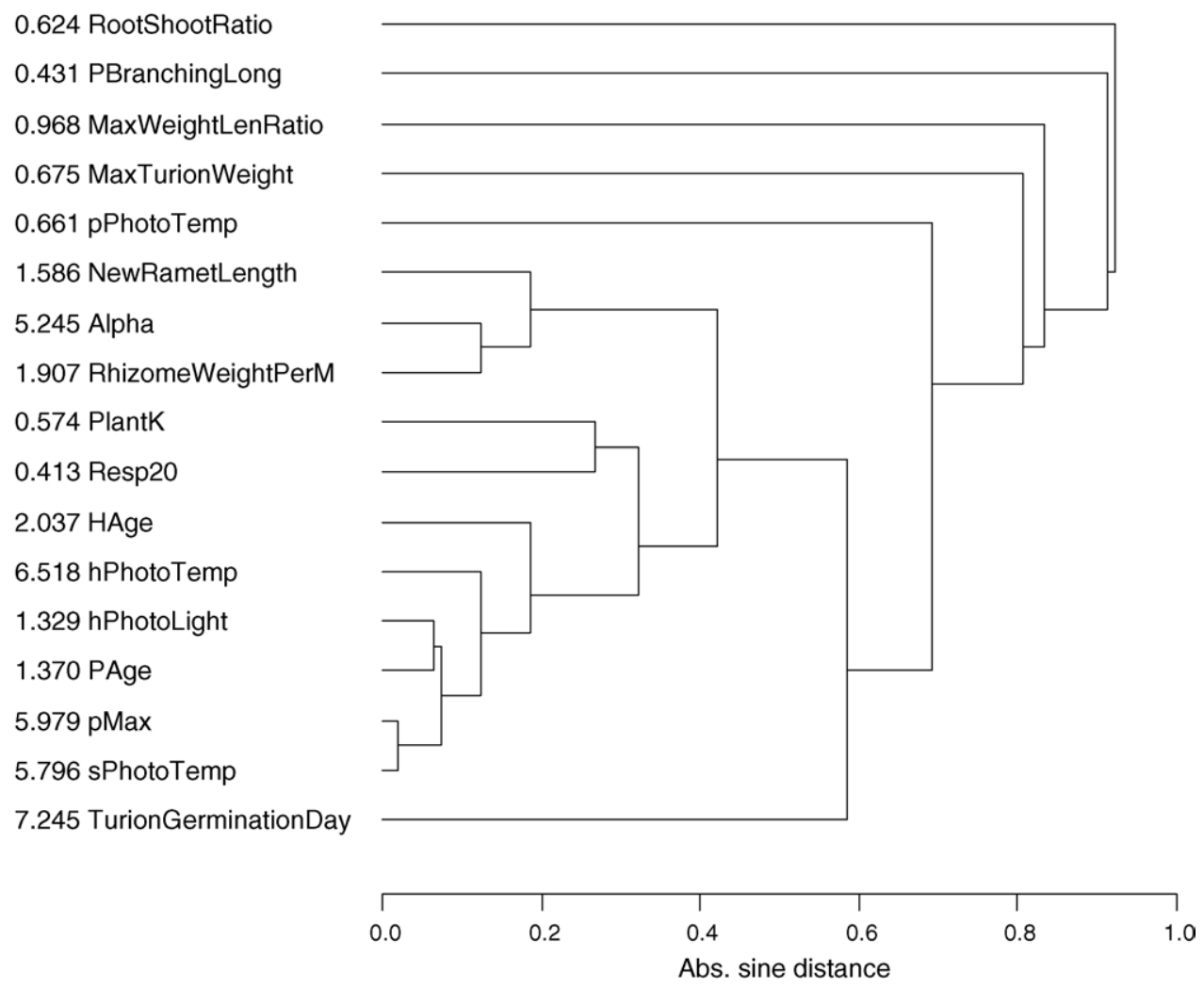

Fig. 10. Cluster analysis of the sensitivity parameters of the model. Parameters with the same or opposite effect on the model results of four subsequent years at three points in time (days 189, 219 and 249). Sensitivity was based on the following model output: mean spacer length, mean shoot length, fraction below-ground biomass, mean number of ramets per clone, approximate expansion area, mean expansion per clone. All parameters shown have a significant effect on model results $(p>0.01)$.

extra parameters that have to be assessed or calibrated. Complex rules have to be set up which make the model complex and prone to uncertainties. The advantage of our model is, that it gives more insight into plant growth strategies than non-architectural mechanistic models. The model allows us to study the effects and implications of specific growth rules for growth characteristics. For example: is branching necessary for successful propagation? It also allows for insights into patch formation and growth.

(2) In contrast to mechanistic models, there are some empirical "design models" of clonal architecture (Bell, 1976; Bell et al., 1979), including submersed species (Molenaar et al., 2000). Empirical models use the ranges and standard deviations of rhizome lengths, branching frequency, branching angles, etc. and generate simulations of growth patterns. They provide insights into possible variability of patterns but cannot explain the underlying mechanisms nor simulate the patterns under different environmental conditions. In contrast, our rhizome architecture is growth related and consequently ruled by environmental factors.

(3) Deterministic and stochastic spatio-temporal models (cellular automata) are also used for clonal plants in competition models (Colasanti and Grime, 1993; Chiarello and Barrat-Segretain, 


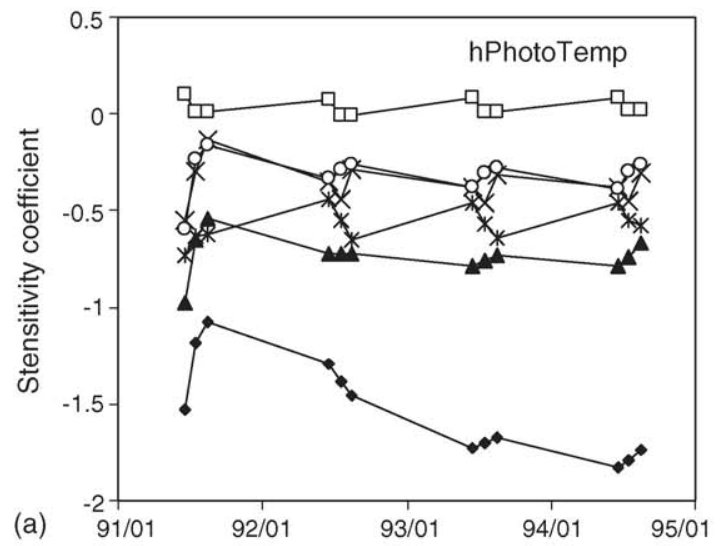

$\rightarrow-$ Approx. expansion area (m2)
$\rightarrow-$ Fraction root and rhizome
$\leftarrow$ Mean expansion per clone $(\mathrm{m})$
$\leftarrow$ Mean length $(\mathrm{m})$
$\rightarrow-$ Mean no. of ramets per clone
$\rightarrow$ - Mean spacer length $(\mathrm{m})$
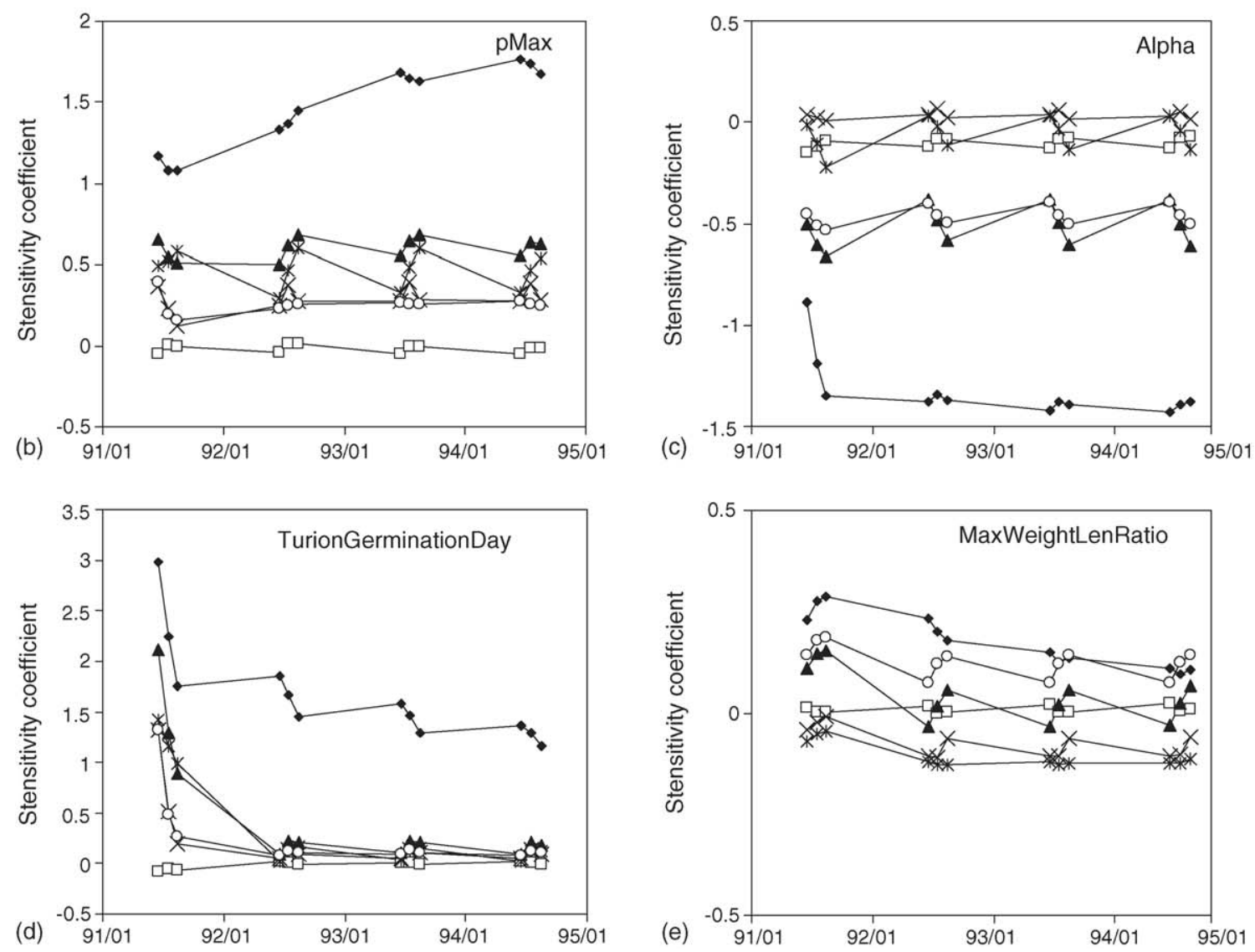

Fig. 11. Time course of the relative sensitivity coefficients of various representative parameters (expressed as sensitivity coefficients) on model outcomes. 
1997; Balzter et al., 1998) but they describe clonal expansion on a grid basis using simple empirical rules, or random processes. They can be used to predict patterns on a larger scale, but being empirical, they do not provide mechanistic insight.

(4) A range of models, mainly for terrestrial plants, takes into account both mechanistic and empirical aspects (Cain and Cook, 1988; Callaghan et al., 1990; Cain, 1994; Oborny, 1994; Cain et al., 1995, 1996; Evans and Cain, 1995; Klimes, 2000), but neither of these models deals with submersed macrophytes nor clonal integration.

(5) Models of clonal integration exist for theoretical plants and are usually non-spatial (Stuefer et al., 1998; Suzuki, 2002). Only a few spatial models include clonal integration (Oborny et al., 2000; Chesson and Peterson, 2002; Herben and Suzuki, 2002; Oborny and Kun, 2002), but in contrast to our model these models are not truly mechanistic, ignore clonal architecture or have a rigid architecture, i.e. do not assume any plastic adjustment of clonal architecture to resource availability.

To our knowledge there is no other model that includes all following components: submersed species, mechanistic biomass growth (dependent on environment), individually based, spatially concise, non-rigid clonal architecture, and clonal integration.

\subsection{Controlling complexity of the model}

Being complex and detailed, our model has also several drawbacks (Van Nes and Scheffer, 2005). The model includes many unknown parameters and processes, resulting in a high uncertainty of the results. Although our results were qualitatively correct, we cannot be sure that we get good results for the correct reason. Therefore, it is not sure whether this model can also be applied to other lakes and sites.

In particular, the results of the simulation of branching variability are sensitive to some parameters for which we do not have good field data, such as fraction of biomass allocated to turions or minimum turion weight for sprouting. The description of poorly known processes was kept as simple as possible in the model, ignoring more flexible plant strategies like the avoidance of small side branches or the formation of a few big turions in order to avoid propagules beyond the weight required for sprouting. Moreover, the model does not include biomass allocation strategies and foraging by means of rhizome length control, as we lack sufficient knowledge of these processes.

We tried to manage the complexity of the model by implementing detailed visualisation of the results, which we regard as essential for keeping track of the complexity (Grimm, 2002). Our modelling environment could visualise the clones and the various features of the ramets, including shoot length, roots and rhizomes, transport between shoot and rhizomes and between rhizomes and patch expansion in 2D and 3D graphs. Furthermore it was essential that the generated patterns could be compared with real data of Potamogeton perfoliatus in Lake Constance at the same level of detail (Wolfer and Straile, 2004a,b). Keeping track of several properties of the clones (spacer length, biomass, number of ramets) simultaneously, we could reduce the probability of getting realistic results for wrong reasons. Finally, we compared our results with a simpler version of the model (Van Nes and Scheffer, 2005), namely the original Charisma model. This way we could show that some behaviour of the model, like the existence of alternative stable states, is not sensitive to the complexity of clonal growth.

The benefits of our model approach are detailed ecological insights through qualitatively correct results. The model has also provided first insights into the understanding of growth architecture and patch expansion of submersed macrophytes. The strong graphical user interface makes it possible to analyse the existing patterns and find the underlying mechanisms. In future, the model will be used for more detailed analyses and for the generation of hypotheses about macrophyte growth rules which can be tested experimentally. It can easily be extended by additional parameters and processes, for example wave mortality or heterogeneous grid cells in order to provide an improved picture of the growth of submersed macrophytes.

\section{Acknowledgement}

We gratefully acknowledge financial support by the Special Collaborative Project (SFB) 454 Bodenseelitoral and RIZA/Lelystad. 


\section{References}

Asaeda, T., Karunaratne, S., 2000. Dynamic modeling of the growth of Phragmites australis: model description. Aquat. Bot. 67, 301-318.

Balzter, H., Braun, P.W., Köhler, W., 1998. Cellular automata models for vegetation dynamics. Ecol. Mod. 107, 113-125.

Barko, J.W., James, W.F., 1997. Effects of submerged aquatic macrophytes on nutrient dynamics, sedimentation, and resuspension. In: Jeppesen, E., Søndergaard, M., Christoffersen, K. (Eds.), The Structuring Role of Submerged Macrophytes in Lakes. Springer, New York, pp. 197-214.

Bell, A.D., 1976. Computerized vegetative mobility in rhizomatous plants. In: Lindenmayer, A., Rozenberg, G. (Eds.), Automata, Languages, Development. North-Holland, Amsterdam, pp. 3-14.

Bell, A.D., Roberts, D., Smith, A., 1979. Branching patterns: simulation of plant architecture. J. Theor. Biol. 81, 351-375.

Best, E.-P.H., Buzzelli, C.P., Doyle, R.D., Wetzel, R.L., Boyd, W.A., Campbell, K.R., 2001. Modeling submersed macrophyte growth in relation to underwater light climate: modeling approaches and application potential. Hydrobiologia 4441, 43-70.

Cain, M.L., 1994. Consequences of foraging in clonal plant species. Ecology 75, 933-944.

Cain, M.L., Cook, R.E., 1988. Growth in Medeola virginiana clones. II Stochastic simulation of vegetative spread. Am. J. Bot. 75, 730-736.

Cain, M.L., Dudle, D.A., Evans, J.P., 1996. Spatial models of foraging in clonal plant species. Am. J. Bot. 83, 76-85.

Cain, M.L., Pacala, S.W., Silander Jr., J.A., Fortin, M.-J., 1995. Neighborhood models of clonal growth in the white clover Trifolium repens. Am. Nat. 145, 888-917.

Calado, G., Duarte, P., 2000. Modelling growth of Ruppia cirrhosa. Aquat. Bot. 68, 29-44.

Callaghan, T.V., Svensson, B.M., Bowman, H., Lindley, D.K., Carlsson, B.Å., 1990. Models of clonal plant growth based on population of dynamics and architecture. Oikos 57, 257-269.

Carr, G.M., Duthie, H.C., Taylor, W.D., 1997. Models of aquatic plant productivity: a review of the factors that influence growth. Aquat. Bot. 59, 195-215.

Cebrián, J., Duarte, C.M., 2001. Detrital stocks and dynamics of the seagrass Posidonia oceanica (L.) Delile in the Spanish Mediterranean. Aquat. Bot. 70, 295-309.

Chen, D.X., Coughenour, M.B., 1996. A mechanistic model for submerged aquatic macrophyte photosynthesis: Hydrilla in ambient and elevated $\mathrm{CO}_{2}$. Ecol. Mod. 89, 133-146.

Chesson, P., Peterson, A.G., 2002. The quantitative assessment of the benefits of physiological integration in clonal plants. Evol. Ecol. Res. 4, 1153-1176.

Chiarello, E., Barrat-Segretain, M.-H., 1997. Recolonization of cleared patches by macrophytes: modelling with point processes and random mosaics. Ecol. Mod. 96, 61-73.

Colasanti, R.L., Grime, J.P., 1993. Resource dynamics and vegetation processes: a deterministic model using two-dimensional cellular automata. Funct. Ecol. 7, 169-176.

Collins, C.D., Wlosinski, J.H., 1989. A macrophyte submodel for aquatic ecosystems. Aquat. Bot. 33, 191-206.
Coops, H., Boeters, R., Smit, H., 1991. Direct and indirect effects of wave attack on helophytes. Aquat. Bot. 41, 333-352.

Davis, J.F., McDonnell, A.J., 1997. Development of a partitionedbiomass model for rooted macrophyte growth. Aquat. Bot. 56, 265-276.

De Kroon, H., Hutchings, M.J., 1995. Morphological plasticity in clonal plants: the foraging concept reconsidered. J. Ecol. 83, 143-152.

Duarte, C.M., Sand-Jensen, K., 1990. Seagrass colonization: biomass development and shoot demography in Cymodocea nodosa patches. Mar. Ecol. Prog. Ser. 67, 97-103.

Evans, J.P., Cain, M.L., 1995. A spatially explicit test of foraging behavior in a clonal plant. Ecology 76, 1147-1155.

Evans, J.P., Whitney, S., 1992. Clonal integration across a salt gradient by a nonhalophyte, Hydrocotyle bonariensis (Apiaceae). Am. J. Bot. 79, 1344-1347.

Gafny, S., Gasith, A., 1991. Spatially and temporally sporadic appearance of macrophytes in the littoral zone of Lake Kinneret, Israel taking advantage of a window of opportunity. Aquat. Bot. 62, 249-267.

Goudriaan, J., 1986. A simple and fast numerical method for the computation of daily totals of crop photosynthesis. Agric. For. Meteorol. 38, 249-254.

Grimm, V., 2002. Visual debugging: a way of analyzing, understanding and communicating bottom-up simulation models in ecology. Nat. Res. Mod. 15, 23-38.

Hartnett, D.C., Bazzaz, F.A., 1983. Physiological integration among intraclonal ramets in Solidago canadensis. Ecology 64, 779-788.

Herben, T., Suzuki, J., 2002. A simulation study of the effects of architectural constraints and resource translocation on population structure and competition in clonal plants. Evol. Ecol. 15, 403-423.

Hootsmans, M.J.M., 1994. A growth analysis model for Potamogeton pectinatus L. In: Van Vierssen, W., Hootsmans, M., Vermaat, J. (Eds.), Lake Veluwe. A Macrophyte-Dominated System under Eutrophication Stress. Kluwer Academic Publishers, Dordrecht, pp. 250-286.

Hootsmans, M.J.M., 1999. Modelling Potamogeton pectinatus: for better or for worse. Hydrobiologia 415, 7-11.

Hutchings, M.J., Wijesinghe, D.K., 1997. Patchy habitats, division of labour and growth dividends in clonal plants. Trends Ecol. Evol. 12, 390-394.

Ikusima, I., 1970. Ecological studies on the productivity of aquatic plant communities IV. Light condition and community photosynthetic production. Bot. Magaz. Tokyo 83, 330-341.

Klepper, O., 1989. A model of carbon flows in relation to macrobenthic food supply in the Oosterschelde estuary (S.W. Netherlands). Ph.D. Thesis, Wageningen University, The Netherlands.

Klepper, O., Van der Tol, M.W., Scholten, H., Herman, P.M., 1994. Smoes-a simulation model for the Oosterschelde ecosystem. 1. Description and uncertainty analysis. Hydrobiologia 283, 437-451.

Klimes, L., 2000. Phragmites australis at an extreme altitude: Rhizome architecture and its modelling. Folia Geobot. Phytotaxon. 35, 403-417.

Lauridsen, T.L., Pedersen, L.J., Jeppesen, E., Søndergaard, M., 1996. The importance of macrophyte bed size for cladoceran composi- 
tion and horizontal migration in a shallow lake. J. Plankton Res. 18, 2283-2294.

Madsen, J.D., Adams, M.S., 1989. The light and temperature dependence of photosynthesis and respiration in Potamogeton pectinatus L. Aquat. Bot. 36, 23-32.

Marbà, N., Hemminga, M.A., Mateo, M.A., Duarte, M.D., Mass, Y.E.M., Terrados, J., Gacia, E., 2002. Carbon and nitrogen translocation between seagrass ramets. Mar. Ecol. Prog. Ser. 226, $287-300$

Molenaar, H., Barthélémy, D., De Reffye, P., Meinesz, A., Mialet, I., 2000. Modelling architecture and growth patterns of Posidonia oceanica. Aquat. Bot. 66, 85-99.

Muhammetoglu, A.B., Soyupak, S., 2000. A three-dimensional water quality-macrophyte interaction model for shallow lakes. Ecol. Mod. 133, 161-180.

Oborny, B., 1994. Growth rules in clonal plants and environmental predictability-a simulation study. J. Ecol. 82, 341-351.

Oborny, B., Kun, Á., 2002. Fragmentation of clones: how does it influence dispersal and competitive ability? Evol. Ecol. 15, 319-346.

Oborny, B., Kun, Á., Tamás, C., Szilárd, B., 2000. The effect of clonal integration on plant competition for mosaic habitat space. Ecology 81, 3291-3304.

Scheffer, M., 1998. Ecology of Shallow Lakes. Chapman \& Hall, London.

Scheffer, M., Bakema, A.H., Wortelboer, F.G., 1993. MEGAPLANT: a simulation model of the dynamics of submerged plants. Aquat. Bot. 45, 341-356.

Scheffer, M., Baveco, J.M., DeAngelis, D.L., Van Rose, K.A., 1995. Super-individuals a simple solution for modelling large populations on an individual basis. Ecol. Mod. 80, 161-170.

Spencer, D.F., Ksander, G.G., Madsen, J.D., Owens, C.S., 2000. Emergence of vegetative propagules of Potamogeton nodosus, Potamogeton pectinatus, Vallisneria americana, and Hydrilla verticillata based on accumulated degree-days. Aquat. Bot. 67, 237-249.

Spencer, D.F., Rejmanek, M., 1989. Propagule type influences competition between two submersed aquatic macrophytes. Oecologia 81, 132-137.

Spencer, D.F., Van Vierssen, W., Ryan, F.J., Ksander, G.G., 1993. Influence of photoperiod and plant weight on tuber production by Potamogeton-pectinatus L. J. Freshw. Ecol. 8, 111.

Stuefer, J.F., De Kroon, H., During, H.J., 1996. Exploitation of environmental heterogeneity by spatial division of labour in a clonal plant. Funct. Ecol. 10, 328-334.
Stuefer, J.F., During, H.J., Schieving, F., 1998. A model on optimal root-shoot allocation and water transport in clonal plants. Ecol. Mod. 111, 171-186.

Suzuki, J., 2002. Shoot growth dynamics and the mode of competition of two rhizomatous Polygonum species in the alpine meadow of Mt. Fuji. Folia Geobot. Phytotaxon. 29, 203-216.

Thompson, J.D., Gray, A.J., McNeilly, T., 1990. The effects of density on the population dynamics of Spartina anglica. Acta Oecol. 11, 669-682.

van Dijk, G.M., Janse, J.H., 1993. Modeling resource allocation in Potamogeton pectinatus L. J. Aquat. Plant Manage. 31, 128-134 (Jan spec ed).

Van Nes, E.H., Scheffer, M., 2005. A strategy to improve the contribution of complex simulation models to ecological theory. Ecol. Mod. 185, 153-164.

Van Nes, E.H., Scheffer, M., Van Den Berg, M.S., Coops, H., 2002. Dominance of charophytes in eutrophic shallow lakes-when should we expect it to be an alternative stable state? Aquat. Bot. 72, 275-296.

Van Nes, E., Scheffer, M., Van Den Berg, M., Coops, H., 2003. Charisma: a spatial explicit simulation model of submerged macrophytes. Ecol. Mod. 159, 103-116.

Walser, R., 1996. Zur Rolle der Makrophytenbestände im Bereich von Flußmündungen am Bodensee-Obersee. Ph.D. Thesis, Universität Hohenheim, Germany, 202 pp.

Watson, M.A., Cook, C.S., 1982. The development of spatial pattern in clones of an aquatic plant, Eichhornia crassipes Solms. Am. J. Bot. 69, 248-253.

Weaver, M.J., Magnuson, J.J., Clayton, M.K., 1997. Distribution of littoral fishes in structurally complex macrophytes. Can. J. Fish. Aquat. Sci. 54, 2277-2289.

Webster, P.J., Rowden, A.A., Attrill, M.J., 1998. Effect of shoot density on the infaunal macro-invertebrate community within a Zostera marina seagrass bed. Estuar. Coast. Shelf Sci. 47, 351-357.

Wijesinghe, D.K., Handel, S.N., 1994. Advantages of clonal growth in heterogeneous habitats: an experiment with Potentilla simplex. J. Ecol. 82, 495-502.

Wolfer, S.R., Straile, D., 2004a. Density control in Potamogeton perfoliatus L. and Potamogeton pectinatus L. Limnologica 34, 98-104.

Wolfer, S.R., Straile, D., 2004b. Spatio-temporal dynamics and plasticity of clonal architecture in Potamogeton perfoliatus L. Aquat. Bot. 78, 307-318.

Wortmann, J., Hearne, J.W., Adams, J.B., 1997. A mathematical model of an estuarine seagrass. Ecol. Mod. 98, 137-149. 